\title{
FERTILIZER BASED AGRI DRONE
}

\section{NIVETHITHA.S.B, LEANDO.I, NARESHBABU.G \& KEERTHANA.D}

Assistant Professor, Rajalakshmi Engineering College, Chennai

\section{ABSTRACT}

Agriculture plays a pivotal role in the economy of a country and undebatable an important part of everyone's life. Nowadays the yield of crops has been reduced due to either absence or excessive presence of nutrients in the soil. There is an urgent need to monitor the presence of nutrients in the soil for a healthy and profitable yield. Our project focuses on acquiring these nutrient details of the crops using an Unmanned Aerial Vehicle (UAV) which has a Receiver transmitter pair that acquires the details of the soil. These details can be brought to the knowledge of the farmer using a display so that either farmer or a separate bot can prepare a proportional fertilizer mixture for maximum yield which can be spread either manually or by the same UAV. This project benefits the farmer by maximizing the yield and making the crops healthy. This project can also help the farmer to decide the crop which might give an optimum yield and making the crops healthy under the given soil conditions.

KEYWORDS: Agriculture, Economy, Nutrient Details, Maximum Yield

Received: Jun 10, 2020; Accepted: Jun 30, 2020; Published: Jul 27, 2020; Paper Id.: IJMPERDJUN2020476

\section{INTRODUCTION}

Agriculture is the technology and art of cultivating plant life and livestock. Agriculture changed into the important thing development within the upward thrust of secondary human civilization, wherein farming of domesticated species created food surpluses that enabled humans to stay in towns. The history of agriculture started out hundreds of years in the past.

The agriculture region goes to face huge challenges with a view to feeding the nine. 6 billion people that the FAO predicts the planet by 2050 . Food production should boom by $70 \%$ by way of 2050 , and this needs to be performed notwithstanding the restrained availability of arable lands, the growing need for freshwater and different less predictable factors.

An agricultural drone is an unmanned aerial car carried out to the farm to assist boom crop manufacturing and reveal crop increase. Agricultural drones permit farmers to look at their fields from the sky. This bird's-eye view can screen many troubles collectively with irrigation problems, soil variants, and pest and fungal infestations.

As drones entered use in agriculture, the Federal Aviation Administration (FAA) endorsed farmers to use this new generation to reveal their fields. Though, with the sudden growth of agricultural drones, the FAA fast pullin such encouragement, pending new rules and regulations.

In our project, we are producing an agricultural drone which is an aerial vehicle that goes above the land and analyses the land and decides the composition of fertilizer to be poured on the agricultural land. 


\section{METHODOLOGY AND METHODS}

The main objective of our project is to monitor the soil nutrition data and to decide the required fertilizer in real-time by integrating Unmanned aerial vehicle along with the led, photodiode with an embedded system.

Unmanned aerial vehicle (UAV) is a plane without a human pilot onboard and a type of unmanned vehicle. UAVs are a component of an unmanned plane device (UAS); which includes a UAV, a ground-based total controller, and a machine of communications among the two. The flight of UAVs may additionally operate with diverse ranges of autonomy: both beneath remote manipulate by way of a human operator or autonomously by using onboard computer systems. UAVs are commonly called a drone.

The drone that we are using is called quadcopter. By using this quadcopter which is integrated with components is used to analyze the soil.

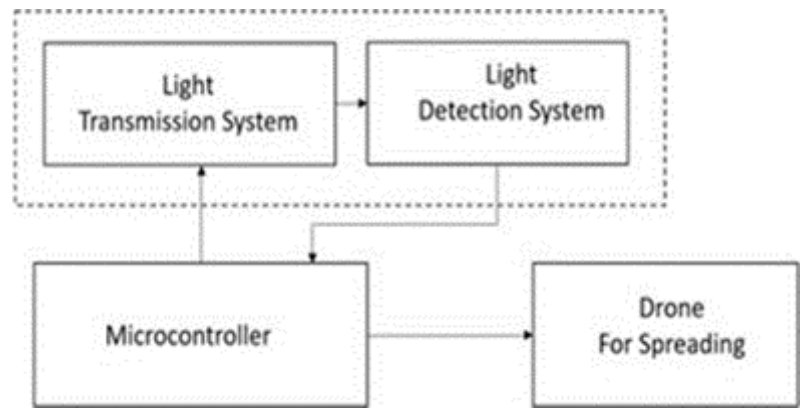

Figure 1: Block Diagram.

Led light falls on the soil and reflects. The reflected light falls on the photodiode which gives the reading. The reading that photodiode gives when light falls on it is known. The known values are compared with the values given by the reflected light. The changes in reading can be used to get the NPK level in the soil through calibration.

The calibrated values give the NPK level in the soil. By using this NPK values, we can spread the required fertilizer in the soil. Thus, the correct fertilizer level can be poured in the soil. So, problems due to fertilizer deficiency and over usage can be reduced in the larger count.

From the referred papers we got a clarity that from the absorption spectrum of the different elements present in the soil, LEDs of different wave length and a photodiode can be used to acquire the range of the elements present in the soil.

Table 1: Nutrient and Wavelength

\begin{tabular}{|l|c|c|c|}
\hline \multicolumn{1}{|c|}{ Nutrient } & $\begin{array}{c}\text { Absorption } \\
\text { Wavelength (nm) }\end{array}$ & LED Type & Wavelength(nm) \\
\hline Nitrogen (N) & $438-490$ & LED 1 & $430-470$ \\
\hline Phosphorous (P) & $528-579$ & LED 2 & $520-530$ \\
\hline Potassium (K) & $605-650$ & LED 3 & $630-640$ \\
\hline
\end{tabular}

From the below table, due to different wavelengths, the reading of the photodiode varies accordingly with the use of LEDs. From this, the range of Nitrogen, Phosphorous and Potassium can be calculated through the microcontroller. 


\section{Manual Using Chemicals}

The photodiode gives out an analog value corresponding to the values of Nitrogen, Phosphorous and Potassium but these values have to be correlated with the original values of the Nitrogen, Phosphorous, and Potassium in the soil. Thus, a soil test kit for NPK values was bought to acquire the original values of NPK soil.

Three soil samples each from different localities were collected and tested using the soil test kit. A soil solution was prepared using the different soil samples and was left to stay for about 20minutes. The samples were then being subjected to Nitrogen, Phosphorous and Potassium Tests separately and the range of Nitrogen, Phosphorous and Potassium values were being found.

From comparing the color of the solution acquired with the color chart given in the kit itself and the below references were obtained.

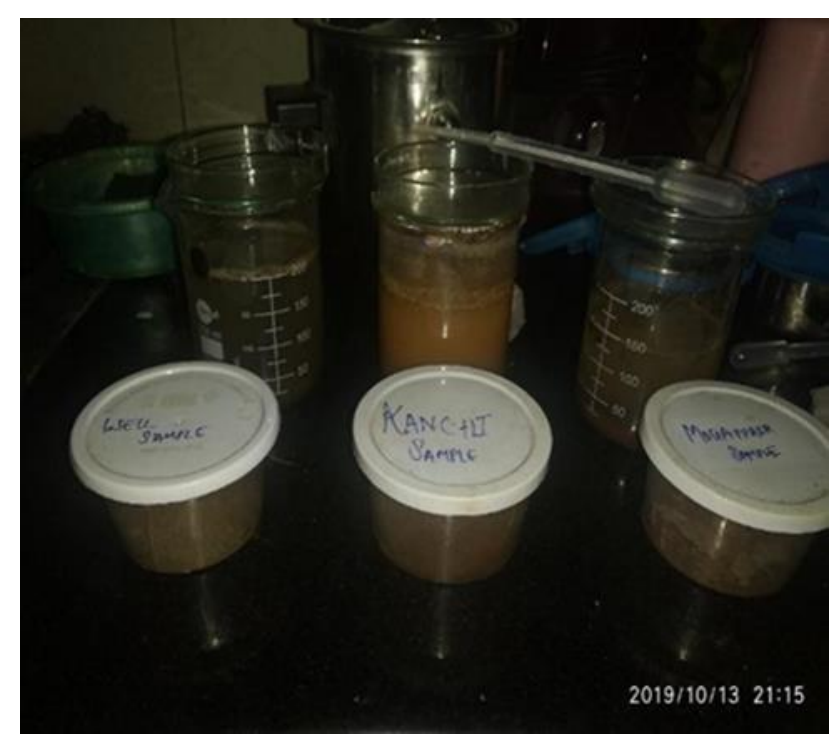

Figure 2: Soil Samples.

Table 2: Soil Samples and NPK Test

\begin{tabular}{|l|c|c|c|}
\hline Soil Sample & Nitrogen & Phosphorous & Potassium \\
\hline Sample 1 & $30-40$ & $25-35$ & $25-50$ \\
\hline Sample 2 & $20-30$ & $25-35$ & $25-50$ \\
\hline Sample 3 & $30-40$ & $35-45$ & $100-150$ \\
\hline
\end{tabular}

From the values of the table, the readings from the photodiode were calibrated.

\section{Calibration with Photodiode Readings}

The readings from the test sampleswerebeingtriedtosynchronizedwiththephotodiodereadingsfrom the micro controller. The output of the photodiode varied proportionally with the LED and the various type of soil being used. Thus, the calibration was being easily done. The photodiode was being used on another sample of soil whose NPK values were unknown and the values from the microcontroller and the chemical test were in par with each other. Thus, the Nitrogen, Phosphorousand Potassium values after calibration when tested on random soil was almost accurate with the manual method and the App was working perfectly fine. 


\section{DESIGN OF DRONE}

The completed drone that we are going to cast -off is called as quad copter which is also referred to as a quad rotor helicopter or quad rotor is a multi-rotor helicopter that is lifted and propelled by four rotors. quad copters are classified as rotorcraft, rather than a fixed-wing plane because their raise is generated by means of a hard and fast of rotors.

The quad copter design can be seen through the block diagram given below,

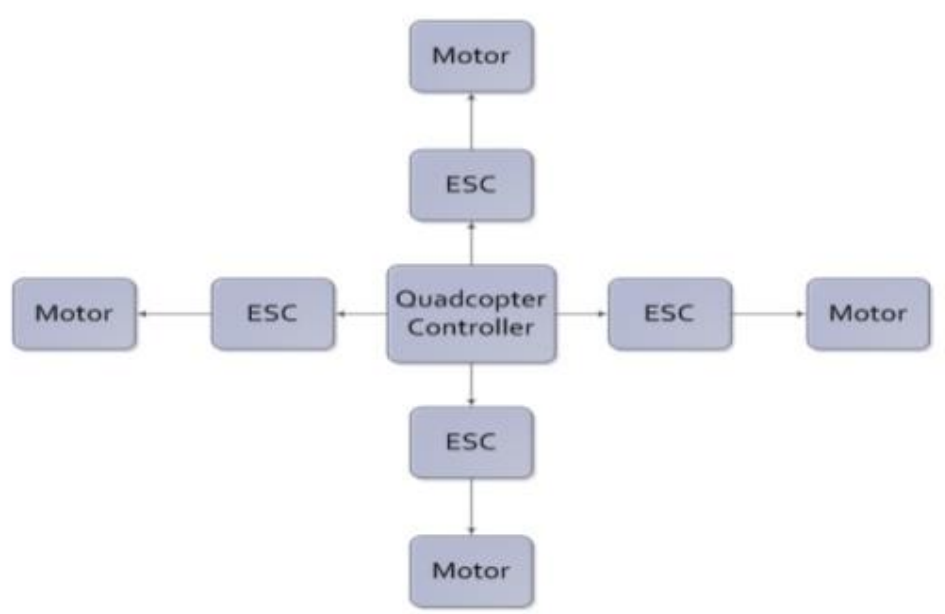

Figure 3: Drone Block Diagram.

From this block diagram, it is seen that the there is four BLDC motor which is connected to the ESC (electronic speed controller) then connected to the flight controller this controller is also connected to the receiver and wireless transmission occur to the transmitter. The controller is given with power supply using LIPO battery along with battery charger.

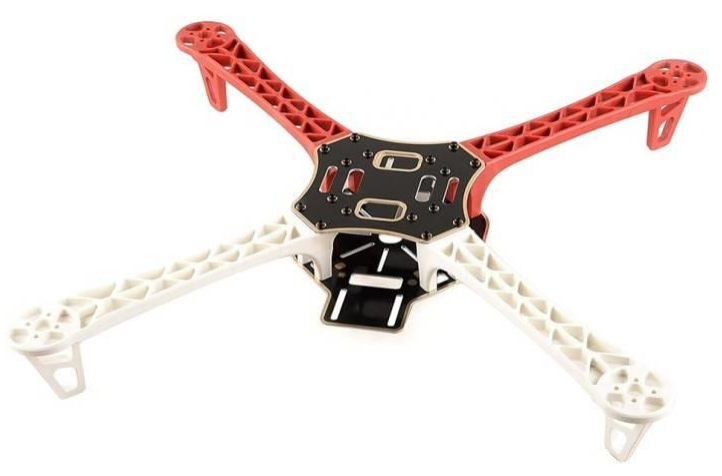

Figure 4: F450 Quad Copter Frame. 


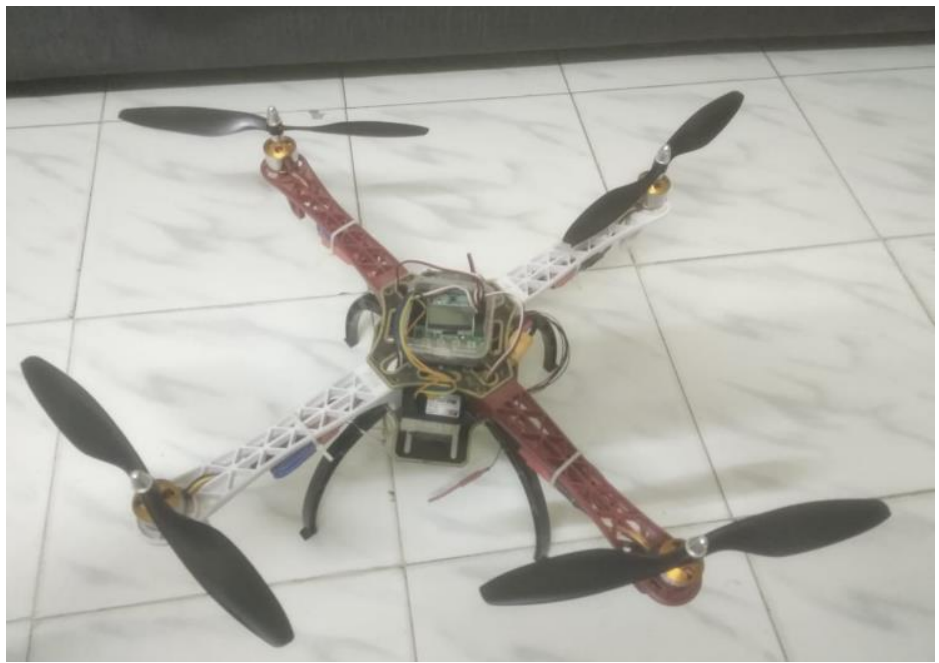

Figure 5: F450 Quad Copter.

\section{TEST CONDUCTED}

The photodiode gives out an analog value corresponding to the values of Nitrogen, Phosphorous and Potassium. But these values have to be correlated with the original values of the Nitrogen, Phosphorous and Potassium in the soil. Thus, a soil test kit for NPK values was bought to acquire the original values of NPK soil.

Three soil samples each from different localities were collected and tested using the soil test kit. A soil solution was prepared using the different soil samples and was let to stay for about 20 minutes.

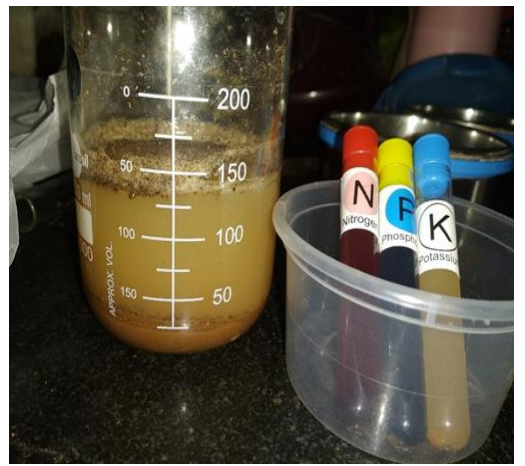

Figure 6: Soil Sample Test 1.

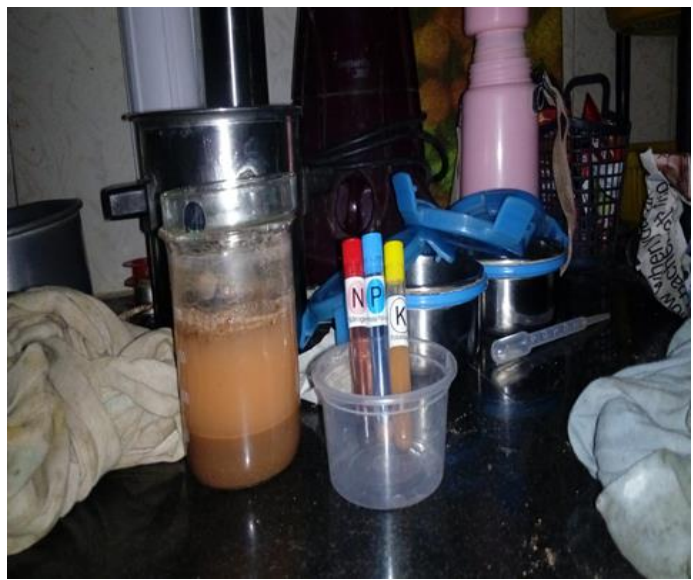

Figure 7: Soil Sample Test 2. 


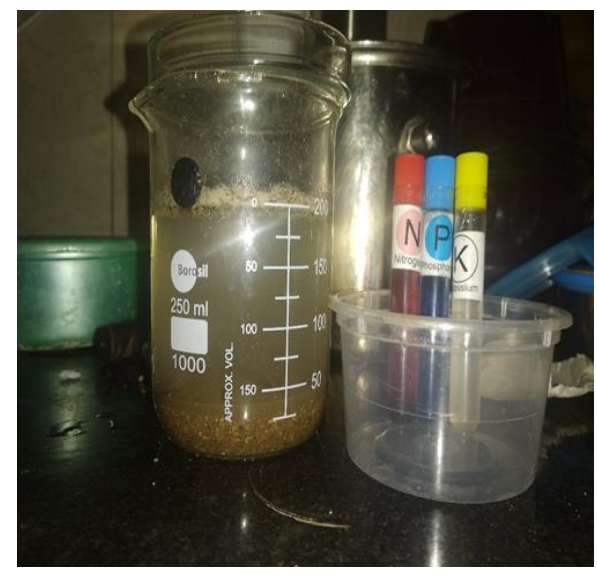

Figure 8: Soil Sample Test 3.

The samples were then being subjected to Nitrogen, Phosphorous and Potassium Tests separately and the range of Nitrogen, Phosphorous and Potassium values were being found.

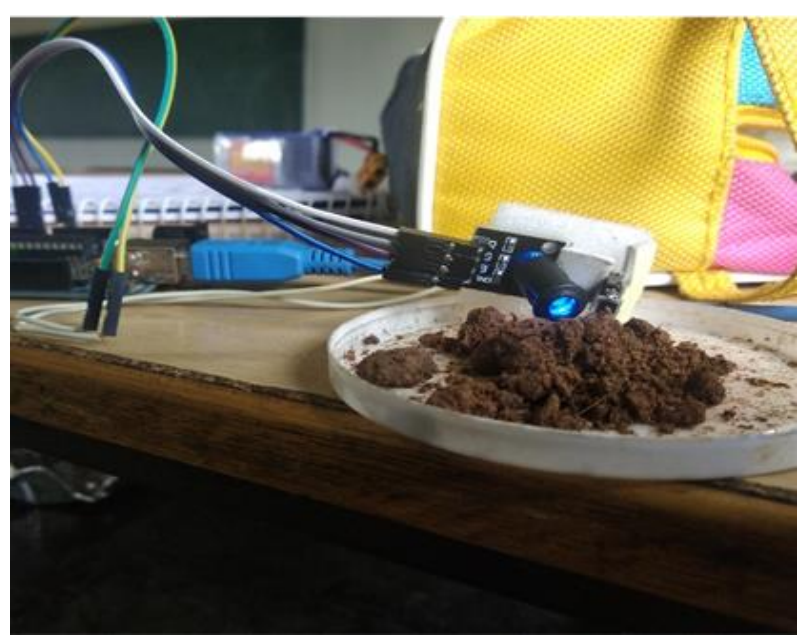

Figure 9: Soil Sample Test Result 1.

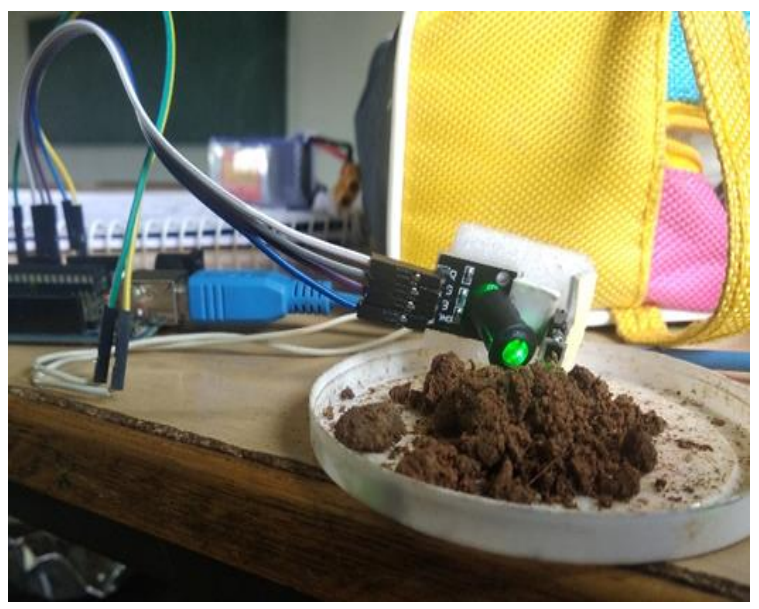

Figure 10: Soil Sample Test Result 2. 


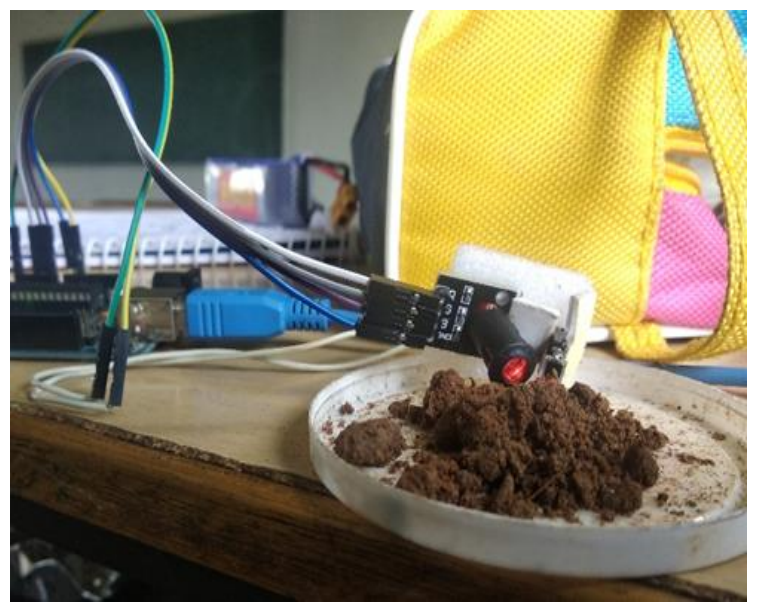

Figure 11: Soil Sample Test Result 3.

Table 3: Soil Samples and NPK Results

\begin{tabular}{|l|c|c|c|}
\hline Soil Sample & Nitrogen & Phosphorous & Potassium \\
\hline Sample 1 & $30-40$ & $25-35$ & $25-50$ \\
\hline Sample 2 & $20-30$ & $25-35$ & $25-50$ \\
\hline Sample 3 & $30-40$ & $35-45$ & $100-150$ \\
\hline
\end{tabular}

From comparing the colour of the solution acquired with the colour chart given in the kit itself and the below references were obtained. From the values of thes table, the readings from the photodiode were calibrated.

\section{RESULTS AND DISCUSSION}

The Nitrogen, Phosphorous and Potassium values after calibration when tested on random soil was almost accurate with the manual method and the app was working perfectly fine. By testing the Nitrogen, Phosphorous and Potassium values in the soil, the drone is used to pour the fertilizer in the agriculture land.

\section{CONCLUSIONS}

The optical transducer, LEDs and photodiode with Arduino microcontroller as an opportunity technique of dedication of the deficiency $\mathrm{N}, \mathrm{P}$, or $\mathrm{K}$ in the soil is successfully developed and tested. This project can lessen the issues in determining the wide variety of nutrients in the soil at an inexpensive cost with the different eras. It is able to additionally lessen the undesired use of fertilizers to be brought to the soil that may cause useless flora and decrease plant fine and quantity. This could be determined through the light absorption of vitamins by means of the optical transducer and evolved threshold values for every nutrient which decides the extent of nutrients into analog values.

\section{REFERENCES}

1. J. P. Kumar, S. Deshpande and A. Inamdar, 9th Workshop on Hyperspectral Image and Signal Processing: Evolution in Remote Sensing (WHISPERS), Amsterdam, Netherlands, 2018, pp. 1-4.

2. P. R. Harshani, T. Umamaheswari, R. Tharani, S. Rajalakshmi and J. Dharani, International Conference on Soft-computing and Network Security (ICSNS), Coimbatore, 2018, pp. 1-10

3. D. A. Gandhi and M. Ghosal, International Conference on Inventive Research in Computing Applications (ICIRCA), Coimbatore, 2018, pp. 412-414. 
4. R. Athira Krishnan, V. R. Jisha and K. Gokulnath, International Conference on Emerging Trends and Innovations In Engineering And Technological Research (ICETIETR), Ernakulam, 2018, pp. 1-5.

5. M. Masrie, M. S. A. Rosman, R. Sam and Z. Janin IEEE 4th International Conference on Smart Instrumentation, Measurement and Application (ICSIMA), Putrajaya, 2017, pp. 1-4.

6. R. G. Regalado and J. C. Dela Cruz, IEEE Region 10 Conference (TENCON), Singapore, 2016, pp. 2387-2391.

7. Amrutha A, Lekha R and A. Sreedevi, Current Trends and Future Challenges (RCTFC), Thanjavur, 2016, pp. 1-5.

8. D. Gheorghiţă, I. Vîntu, L. Mirea and C. Brăescu, "19th International Conference on System Theory, Control and Computing (ICSTCC), CheileGradistei, 2015, pp. 421-426.

9. M. A. Lukmana and H. Nurhadi, International Conference on Advanced Mechatronics, Intelligent Manufacture, and Industrial Automation (ICAMIMIA), Surabaya, 2015, pp. 34-37.

10. Z. Mustapa, S. Saat, S. H. Husin and T. Zaid, IEEE Symposium on Industrial Electronics \& Applications (ISIEA), Kota Kinabalu, 2014, pp. 130-135.

11. NS, Sarath Raj, et al. "are Drones a Threat to Civil Aviation? A Retrospective on Policies of Drones in the United Arab Emirates." International Journal of General Engineering and Technology (IJGET) 6.4 (2017) : 7-28.

12. Malisuwan, Settapong. "Design of Ground Station Smart Antenna System for Multimedia Communications in Small Drone Applications." International Journal of Computer Networking, Wireless and Mobile Communications (IJCNWMC) 5.6 (2015) : 9-18.

13. Paul, Pampi, and Mukesh Kumar. "Climate Smart Agriculture with Gender Perspective." IMPACT: International Journal of Research in Applied, Natural and Social Sciences (IMPACT: IJRANSS) 4.9 (2016) : 25-32

14. KV, Ramamurthy, and SA Kazi. "Urban Agriculture in Cuba and Exploring Possibilities with Reference to Urban India." BEST: International Journal of Humanities, Arts, Medicine and Sciences (BEST: IJHAMS) 2.8 (2014) : 77-88 